\title{
Plastic deformation simulation of steel panels
}

\author{
Mihaela Savin ${ }^{1, *}$, Adrian Presura ${ }^{2}$, and Ionel Chirica ${ }^{1}$ \\ 1',Dunarea de Jos" University of Galati, Faculty of Engineering, Domneasca Street, No. 47, 800008, \\ Galati, Romania \\ 2"'Dunarea de Jos" University of Galati, Faculty of Naval Architecture, Stiintei Street, No. 2, 800146, \\ Galati, Romania
}

\begin{abstract}
This paper presents the FEM analysis of plastic deformation of different steel panels using a spherical indenter. Two experiments were done: first on a simple steel panel and second on a stiffened steel panel, which were subjected to a static plastic deformation produced with help of a spherical indenter. The results of the practical test were compared with the results of numerical simulations, which were accomplished using ANSYS-Static Structural module.

The tests were realized using an experimental stand based on a screw press mechanism. The tests consist in vertical displacement of the spherical bulb, which in this way deformed the panel leaning on the stand frame. During the tests were measured the force applied to the indenter, with help of an PLC500 force transducer, and the vertical displacement of the panel in the application point of force, with help of an HBM WA/300 displacement transducer.

The results of calculations are presented below as: final deformed models and force-displacement diagrams with the comparison between experiment and numerical simulation.

In conclusion of this research the compared results between the experiments and numerical simulations revealed that can be achieved accurate results using FEM analysis for plastic deformation problems, with proper parameters settings.
\end{abstract}

\section{Introduction}

One of the new topics of modern engineering is the study of the behaviour of various structures in the field of plastic deformations such as body impact, explosion, etc. $[1,2]$

Analysis of impact structures has seen a strong development due to increased safety and environmental protection standards, but also due to tremendous growth of computing technology $[3,4]$.

The study presented in this article proposed to investigate:

- the influence of different parameters on plastic deformation numerical analysis results

- the real margin of error between the FEM analysis and experimental tests.

Two types of steel structures were analysed, simple and stiffened steel panels, which are the basic components of any complex structures. The panels were investigated at side

* Corresponding author: mihaela.savin@ugal.ro 
impact force, which is one of the most common demands in maritime and automotive industry today.

The plastic deformation of steel panels was generated with help of a specially developed experimental stand, based on a screw press mechanism. The stand components, presented in figure 1, are:

- stand frame - made from UNP80 profile

- screw mechanism - M24 screw

- force transducer - $50 \mathrm{kN}$ maximum

- displacement transducer - 300mm maximum

- spherical bulb - $\phi 60 \mathrm{~mm}$

- steel panel with UNP60 profile frame.

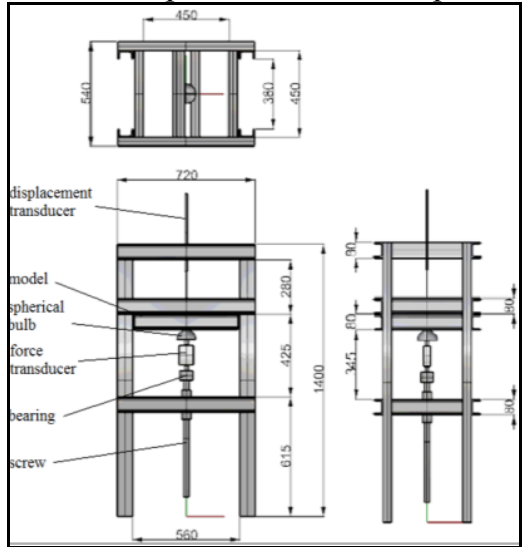

Fig.1 Experimental stand

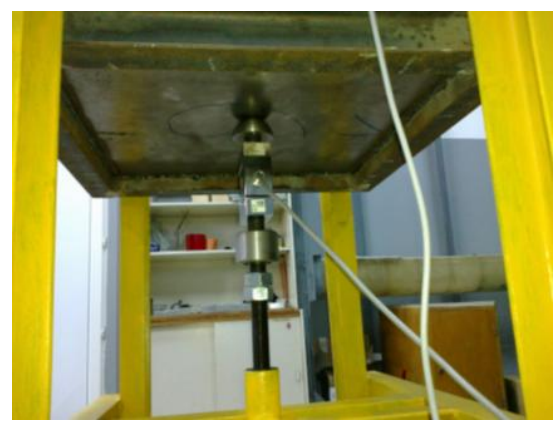

Fig.2 Spherical bulb acting on the panel

In figure 2 above is represented the panel mounted on the stand at the beginning of the test.

The deformation of steel panels was made normal at the surface of the panel through vertical displacement of the spherical bulb, acted by rotating the screw.

\section{Experimental tests}

Experimental tests consisted in plastic deformation of two steel panels:

- model 1 - simple steel panel - 450 x $450 \mathrm{~mm}, 1.5 \mathrm{~mm}$ thickness (figure 3)

- model 2 - stiffened steel panel - 450 x $450 \mathrm{~mm}, 15 \mathrm{~mm}$ height of stiffeners, $1.5 \mathrm{~mm}$ thickness (figure 4).

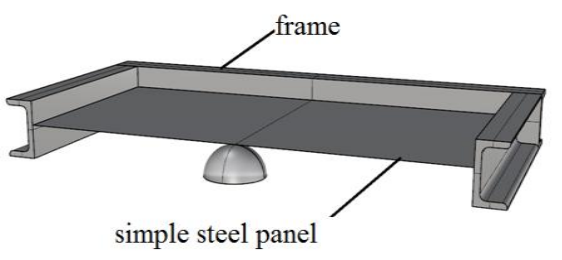

Fig.3 Simple steel panel - model 1

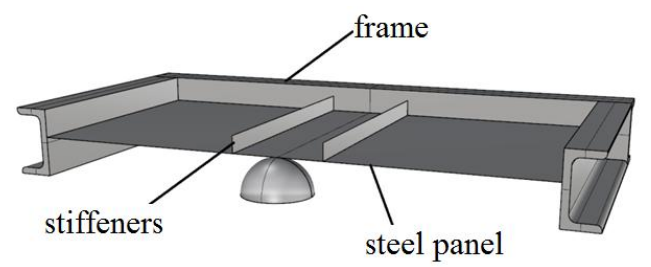

Fig.4 Stiffened steel panel - model 2

Two parameters were measured during the experiment:

- force applied to the spherical bulb and

- vertical displacement of the steel sheet, with help of displacement transducer. 
The force - displacement graphics of the experimental results are presented in figure 5 and 6 below:

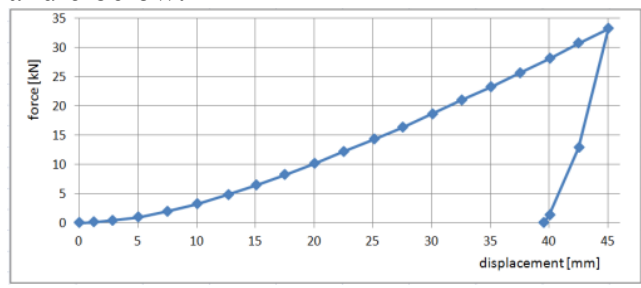

Fig.5 Force-displacement graphic - model 1

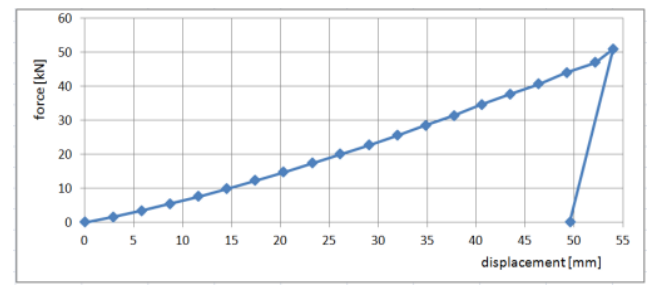

Fig.6 Force-displacement graphic - model 2

By comparing the results of the two models, it can be observed a $17 \%$ increase in force, at same displacement $45 \mathrm{~mm}$, for the stiffened model. below:

The final deformed shape of the steel panels can be observed in the figures 7 and 8

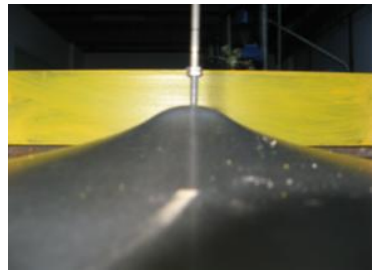

Fig.7 Final plastic deformation - model 1

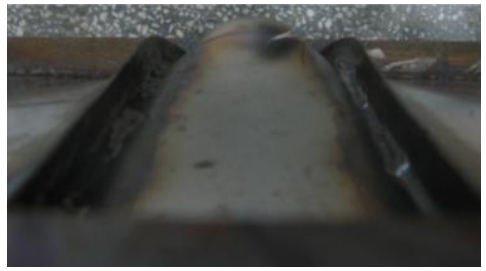

Fig.8 Final plastic deformation - model 2

In plastic deformation phenomena an important parameter is the internal energy absorbed by the structure during deformation. Internal energy variation is equivalent with mechanical work performed by the spherical bulb on the steel panel. By integrating the force function of displacement, the curve of internal energy is obtained as function of displacement for the model. The energy-displacement diagrams of the two steel panels obtained after the experiments are depicted in figure 9 and 10 below:

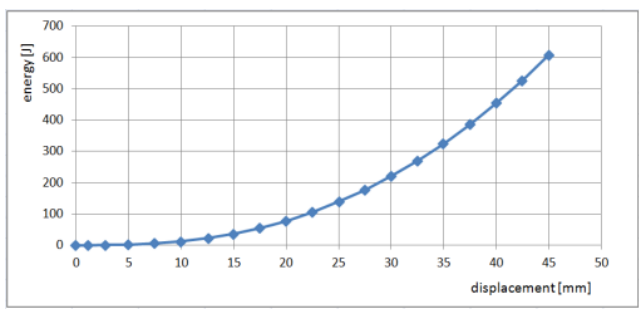

Fig.9 Energy-displacement graphic-model 1

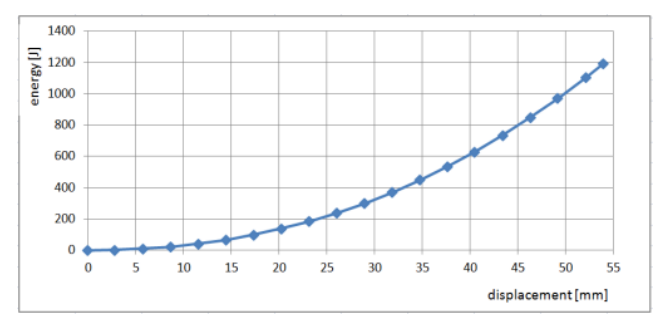

Fig.10 Energy-displacement graphic-model 2

By comparing the internal energy of the two models, it can be observed a $\mathbf{3 3 \%}$ increased energy for the stiffened model, at same displacement $45 \mathrm{~mm}$.

Also part of the experiment, in order to determine the mechanical properties of the steel used at the fabrication of the panel and stiffeners, a number of three specimens were tested on the tensile test machine as shown in the figure 11 below. The geometry of the specimens was realized according „SR EN100002-1:2001 - Annex B - Types of test pieces to be used for thin products: sheets, strips and flats between $0,1 \mathrm{~mm}$ and $3 \mathrm{~mm}$ thick" and is presented in figure 12 [5]. 
The resulting force-elongation diagrams of the three specimens are presented in figure 13 below. The average value of the three curves was the final stress-strain diagram of the steel used in the numerical simulation.

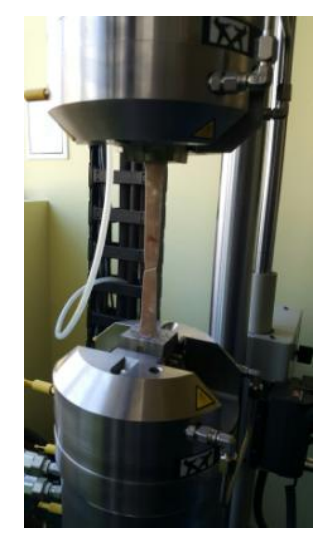

Fig.11 Tensile test

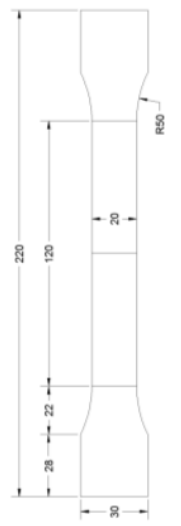

Fig.12 Steel specimen

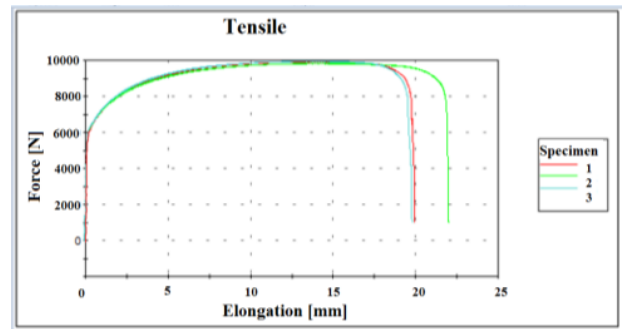

Fig.13 Force-elongation diagram-steel

\section{Numerical simulations}

For numerical analysis of plastic deformation experiment, have been modelled the panel, frame and spherical bulb (figure 14). The scope of this comparative investigation was to establish the numerical simulation parameters that lead to best approximation of experiment results.

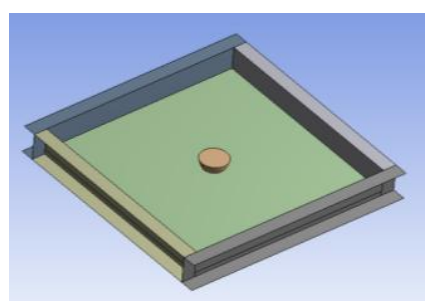

Fig.14 Model used for simulation

Having as reference the force and vertical displacement values measured during experimental tests, it was investigated the influence of different parameters of numerical analysis:

- material idealization

- element type "shell" versus "solid"

- mesh size

- boundary conditions.

\subsection{Material idealization - bilinear isotropic hardening}

For idealization of steel material was used a bilinear isotropic hardening model [6], with the following mechanical characteristics (figure 15):

- Young's modulus $=2.1 \times 10^{5} \mathrm{~N} / \mathrm{mm}^{2}$

- Yield strength $\mathrm{R}_{\mathrm{eH}}=200 \mathrm{~N} / \mathrm{mm}^{2}$

- Tangent modulus $=745 \mathrm{~N} / \mathrm{mm}^{2}$

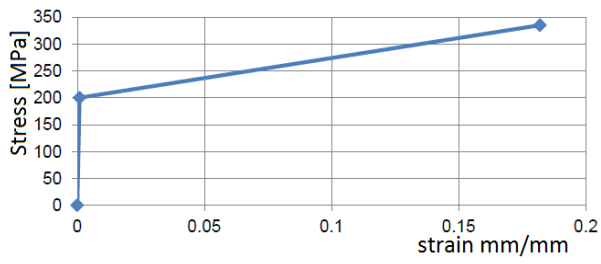

Fig.15 Bilinear material idealization 


\subsection{Element type "shell" versus "solid"}

The comparison between "shell" and "solid" elements simulations revealed a negligible difference of $0.6 \%$ for total deformation and an $15 \%$ difference for stress and force, which are partly due the boundary conditions. Instead the difference of computation time, of near $300 \%$ higher for "solid" elements, led to "shell" elements as the best compromise.

Table.3 Comparative values for "shell" and "solid" elements

\begin{tabular}{|l|c|c|c|}
\hline Comparison criteria & ,shell” & „solid” & Diff.[\%] \\
\hline maximum remanent displacement [mm] & 42.84 & 42.56 & 0.6 \\
\hline maximum equivalent stress [MPa] & 262.32 & 219.97 & 16.1 \\
\hline maximum force in spherical bulb [kN] & 39.393 & 33.630 & 14.6 \\
\hline computation time [seconds] & 217 & 841 & 287 \\
\hline
\end{tabular}

\subsection{Mesh size}

Sixteen different mesh sizes were investigated, as follows:

- 8 mesh sizes: $2,5,10,15,20,25,30,35 \mathrm{~mm}$ for uniform grid - figure 16 , and

- 8 mesh sizes: $2,5,10,15,20,25,30,35 \mathrm{~mm}$ for non uniform grid - figure 17 .

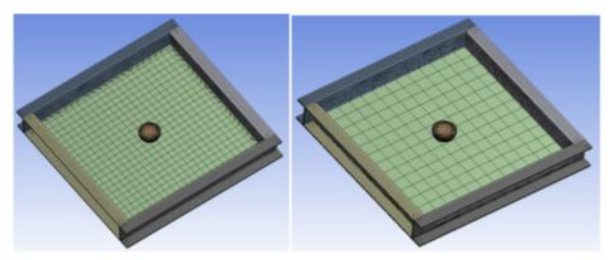

Fig.16 Mesh sizes - uniform grid

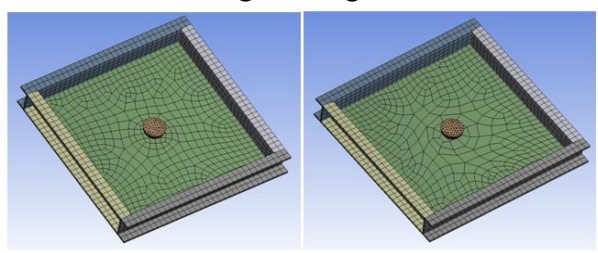

Fig.17 Mesh sizes - non uniform grid

From the comparison of the results presented in table 4 and 5 below and the corresponding experimental results can be drawn the following conclusions:

- for uniform grid - the $10 \mathrm{~mm}$ mesh size provides the smallest error for deformation $2.5 \%$ and $113 \mathrm{~s}$ computation time

- for non uniform grid - the $10 \mathrm{~mm}$ mesh size provides one of the smallest error for deformation $4 \%$ and $58 \mathrm{~s}$ computation time.

Table 4 - uniform grid mesh results

\begin{tabular}{|l|l|l|l|l|l|l|}
\hline Nr. & $\begin{array}{l}\text { Element size } \\
{[\mathrm{mm}]}\end{array}$ & $\begin{array}{l}\text { Deform. } \\
{[\mathrm{mm}]}\end{array}$ & $\begin{array}{l}\text { Deform. } \\
\text { diff. }[\%]\end{array}$ & $\begin{array}{l}\text { Force } \\
{[\mathrm{kN}]}\end{array}$ & $\begin{array}{l}\text { Force diff. } \\
{[\%]}\end{array}$ & $\begin{array}{l}\text { Time } \\
{[\mathrm{s}]}\end{array}$ \\
\hline 0 & Experiment & 39.54 & & 33.22 & & - \\
\hline 1 & 2 & 40.667 & 2.9 & 25.669 & -22.7 & 2385 \\
\hline 2 & 5 & 40.634 & 2.8 & 25.900 & -22.0 & 342 \\
\hline 3 & 10 & 40.538 & 2.5 & 26.916 & -19.0 & 113 \\
\hline 4 & 15 & 42.857 & 8.4 & 27.989 & -15.7 & 110 \\
\hline 5 & 20 & 40.691 & 2.9 & 29.202 & -12.1 & 97 \\
\hline 6 & 25 & 43.328 & 9.6 & 29.448 & -11.4 & 73 \\
\hline 7 & 30 & 41.081 & 3.9 & 33.265 & 0.1 & 98 \\
\hline 8 & 35 & 41.243 & 4.3 & 35.008 & 5.4 & 79 \\
\hline
\end{tabular}

Considering that in general a $5-10 \%$ margin of error is reasonable in structure design, which takes in to account the material factors, joining structural elements, the approximation degree of loadings etc., then it can be said that an appropriate mesh size function of plate thickness is: 
Element length / element thickness $=\sim(5 \ldots 10)$

Table 5 - non uniform grid mesh results

\begin{tabular}{|l|l|l|l|l|l|l|}
\hline Nr. & $\begin{array}{l}\text { Element size } \\
{[\mathrm{mm}]}\end{array}$ & $\begin{array}{l}\text { Deform. } \\
{[\mathrm{mm}]}\end{array}$ & $\begin{array}{l}\text { Deform. } \\
\text { diff. }[\%]\end{array}$ & $\begin{array}{l}\text { Force } \\
{[\mathrm{kN}]}\end{array}$ & $\begin{array}{l}\text { Force diff. } \\
{[\%]}\end{array}$ & $\begin{array}{l}\text { Time } \\
{[\mathrm{s}]}\end{array}$ \\
\hline 0 & experiment & 39.54 & & 33.22 & & - \\
\hline 1 & 2 & 40.703 & 2.9 & 26.455 & -20.4 & 176 \\
\hline 2 & 5 & 41.114 & 4.0 & 26.692 & -19.7 & 97 \\
\hline 3 & 10 & 41.108 & 4.0 & 27.069 & -18.5 & 58 \\
\hline 4 & 15 & 42.107 & 6.5 & 27.209 & -18.1 & 67 \\
\hline 5 & 20 & 41.772 & 5.6 & 27.952 & -15.9 & 55 \\
\hline 6 & 25 & 41.986 & 6.2 & 29.500 & -11.2 & 48 \\
\hline 7 & 30 & 42.754 & 8.1 & 28.670 & -13.7 & 60 \\
\hline 8 & 35 & 41.902 & 6.0 & 31.481 & -5.2 & 71 \\
\hline
\end{tabular}

\subsection{Boundary conditions}

Four different boundary conditions were investigated on simple steel panel:

a) fixed rotations and fixed displacements of panel contour - figure 18

b) free rotations and fixed displacements of panel contour

c) model the panel and contour welding with "solid" elements and fixed rotations and displacements of vertical side of weld - figure 19

d) model the panel together with frame and simple support of the frame - figure 20.

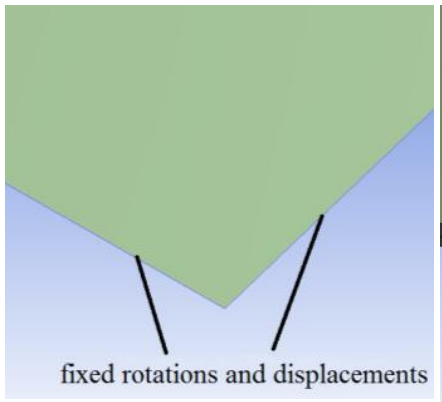

Fig.18 - Boundary - a)

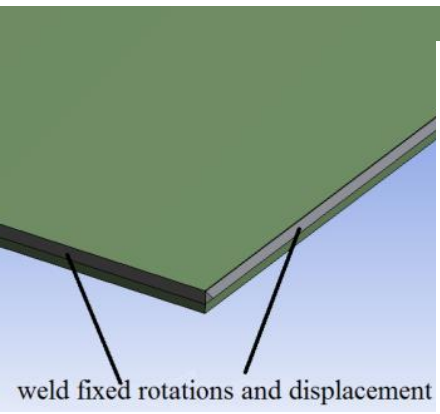

Fig.19 - Boundary - c)

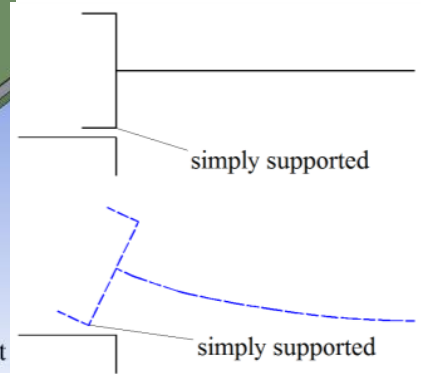

Fig.20 - Boundary - d)

Analyzing the results of different boundary conditions, presented in the table 6 below, in comparison with experimental data, can be summarized the following:

- maximum difference - $8 \%$ - for plastic deformation was obtained for boundary condition a)

- smallest difference - 3\% - for plastic deformation was obtained for boundary condition d)

- similar difference - $20 \%$ - for force was obtained for boundary condition a), b) and d)

- smallest difference - $1 \%$ - for force was obtained for boundary condition c).

From this analysis it can be stated that the four different boundary conditions influenced significantly the results, and the most consistent influences were obtained for the force values. 
In conclusion the boundary conditions must be carefully chosen, and out of caution different conditions must be investigated to see the influence on the finite element analysis results.

Table 6 - different boundary conditions results

\begin{tabular}{|l|l|l|l|l|l|l|}
\hline Nr. & Situation & $\begin{array}{l}\text { Deform. } \\
{[\mathrm{mm}]}\end{array}$ & $\begin{array}{l}\text { Deform. } \\
\text { diff. }[\%]\end{array}$ & $\begin{array}{l}\text { Force } \\
{[\mathrm{kN}]}\end{array}$ & $\begin{array}{l}\text { Force diff. } \\
{[\%]}\end{array}$ & $\begin{array}{l}\text { Time } \\
{[\mathrm{s}]}\end{array}$ \\
\hline 0 & Experiment & 39.54 & & 33.22 & & - \\
\hline 1 & $\mathrm{a}$ & 42.836 & 8.3 & 39.393 & 18.6 & 217 \\
\hline 2 & $\mathrm{~b}$ & 42.602 & 7.7 & 39.235 & 18.1 & 251 \\
\hline 3 & $\mathrm{c}$ & 42.560 & 7.6 & 33.630 & 1.2 & 841 \\
\hline 4 & $\mathrm{~d}$ & 40.634 & 2.8 & 25.900 & -22.0 & 342 \\
\hline
\end{tabular}

\section{CONCLUSIONS}

By comparing the experimental data with the above numerical simulations results, the following useful conclusions can be underlined:

- bilinear idealization of the material leads to good results with low computation time

- "shell" element type represents the best solution for accuracy/computation time ratio

- element length / element thickness $=\sim(5 \ldots 10)$ represents an appropriate aspect ratio

- different boundary conditions can have significant influence on results, especially for contact forces.

As final conclusion of this study it was found that can be achieved a 5-10\% margin error for finite element analysis of steel panels plastic deformation, if proper parameters are used, which satisfy the general margin accepted by structure engineering standards [7].

\section{Acknowledgement}

The present research has been supported by "Dunarea de Jos" University of Galati and Ship Design Group Galati.

\section{References}

1. Chen W.F., Han D.J., Plasticity for Structural Engineers, (Springer Verlag New York Inc., ISBN 3-540-96711-7, 1988)

2. A. Presura, ph.d. thesis Stress states that appear in ship unconventional double hull structures, "Dunarea de Jos" University of Galati, (2017)

3. ADN - European Agreement concerning the International Carriage of Dangerous goods by Inland Waterways - United Nations (2016)

4. MOVEIT! - Modernisation of vessels for inland waterway freight traffic - Work package WP5 Structures \& Weight, Task 5.3 Crashworthiness (2014)

5. SR EN100002-1, Annex B, Types of test pieces to be used for thin products: sheets, strips and flats between $0,1 \mathrm{~mm}$ and $3 \mathrm{~mm}$ thick (2001)

6. DNV RP-C208, Determination of Structural Capacity by Non-linear FE analysis Methods, (2013)

7. CSR OT, Common Structural rules for Double Hull Oil Tankers, IACS, (2012) 